\title{
SOFT LAW COMO HERRAMIENTA DEL COMPLIANCE SOCIOAMBIENTAL*
}

\section{SOFT LAW AS A TOOL OF SOCIO-ENVIRONMENTAL COMPLIANCE}

\author{
LUCIANA CRISTINA DA CONCEIÇÃO LIMA \\ Universidad Católica de Santos \\ https://orcid.org/0000-0001-8729-4125 \\ lulima@icloud.com \\ MARÍA PILAR DOPAZO FRAGUÍO \\ Universidad Complutense de Madrid \\ mdopazo@pdi.ucm.es \\ ALCINDO FERNANDES GONÇALVES \\ Universidad Católica de Santos \\ alcindo@unisantos.br \\ FERNANDO CARDOZO FERNANDES REI \\ Universidad Católica de Santos \\ fernandorei@ig.com.br
}

Fecha de recepción: 15 de julio de 2019 / Fecha de aceptación: 13 de diciembre de 2019

RESUMEN: Actualmente, la necesidad de cumplir con las exigencias socioambientales ya no encuentra espacio en las discusiones sobre la voluntariedad

*Este trabajo es el resultado de las actividades del proyecto de investigación n ${ }^{\circ} 88881.187999 / 2018$-01, financiado pela Capes/Brasil y desarrollado en la Universidad Complutense de Madrid (Departamento de Derecho Administrativo) en España, codirigido por Dra./Dña. Profesora María Pilar Dopazo Fraguío. El proyecto hace parte de la investigación del Doctorado titulado "Normas Técnicas Socioambientales Internacionales: Contribución de la Soft Law a la Efectividad del Derecho Ambiental Internacional", dirigida por el Dr. Profesor Alcindo Gonçalves, en la Universidad Católica de Santos. 
de las organizaciones, tampoco en la gestión individual de las cuestiones socioambientales. El contexto exige actuaciones conjuntas y la cooperación para enfrentar los problemas comunes. No demostrar la atención a esa demanda puede tener impactos que van más allá de las sanciones legales. Hasta el momento, la responsabilidad socioambiental ha sido regulada de forma directa y/o indirecta, a través de diversos mecanismos e instrumentos internacionales, supranacionales y nacionales. En este sentido, el presente ensayo analiza el contexto y la funcionalidad de herramientas técnicas soft law, con el fin de determinar su posible influencia y alcance en la regulación y autorregulación, y, consecuentemente, su contribución para el cumplimiento de la responsabilidad socioambiental corporativa.

RESUM: Actualment, la necessitat de complir amb les exigències socioambientals ja no troba espai en les discussions sobre la voluntarietat de les organitzacions, tampoc en la gestió dels aspectes dels drets humans i mediambientals. El context exigeix actuacions conjuntes i la cooperació per enfrontar-se als problemes comuns. No demostrar atenció en aquesta demanda pot tenir impactes que van més enllà de les sancions legals. Fins avui, la responsabilitat socioambiental s'ha regulat de manera directa o indirecta, amb diversos mecanismes i instruments internacionals, supranacionals i nacionals. En aquest sentit, aquest assaig analitza el context i la funcionalitat d'eines tècniques de dret tou, amb la finalitat de determinar-ne la possible influència i abast en la regulació i autoregulació, i, conseqüentment, la seva contribució per complir la responsabilitat socioambiental corporativa.

ABSTRACT: Currently, the need to comply with socio-environmental requirements no longer finds space in discussions about the voluntary nature of organizations, nor in the individual management of socio-environmental issues. The context demands joint actions and cooperation to face common problems. Failure to show attention to that demand may have impacts that go beyond legal sanctions. So far, socio-environmental responsibility has been regulated directly and/or indirectly, through various international, supranational and national mechanisms and instruments. In this sense, this essay analyzes the context and functionality of soft law technical tools, in order to determine their possible influence and scope in regulation and self-regulation, and, consequently, their contribution to the fulfillment of corporate socio-environmental responsibility. 
PARAULES-CLAU: Responsabilitat socioambiental corporativa - Soft law - Autoregulació - Compliance.

PALABRAS-CLAVE: Responsabilidad Socioambiental Corporativa - Soft Law Autorregulación - Compliance.

KEY-WORDS: Corporate Socio-environmental Responsibility - Soft Law Autoregulation - Compliance.

SUMARIO: Introducción. 1 Gobernanza socioambiental global. 2 La soft law en el contexto de la responsabilidad socioambiental corporativa. $3 \mathrm{La}$ autorregulación como mecanismo para la gobernanza y la conformidad. 4 Conclusión. Referencias Bibliográficas.

\section{INTRODUCCIÓN}

La preocupación por los problemas socioambientales ha sido demostrada en el escenario internacional, a través de la elaboración y adopción de leyes, normas privadas y herramientas técnicas que buscan atender las expectativas y exigencias de la sociedad y de sus múltiples actores. En este contexto, procesos de gobernanza se forman como medio o camino para reunir a los actores interesados en el desarrollo de mecanismos que contribuyan al enfrentamiento de las cuestiones comunes. Estos procesos, que permiten la participación ampliada de los diferentes actores, son esencialmente importantes ante la necesidad de intercambio de informaciones y conocimientos técnicos y científicos para el progreso de la agenda internacional del desarrollo sostenible, que tiene como interés, por un lado, las relaciones políticas, económicas y sociales, y, por otro, la crisis ambiental y de los derechos humanos.

El concepto de gobernanza se amplía y adopta un enfoque más global, a partir de la interdependencia entre los Estados y la consecuente necesidad de acciones conjuntas, pues los problemas, en realidad, no están restringidos a los territorios nacionales ${ }^{1}$, ni a las normas domésticas que, sin embargo, no han sido de todo

\footnotetext{
${ }^{1}$ GEIGEL, Nelson. Derecho ambiental internacional. Universidad Simón Bolívar. Ediciones Equinoccio. Venezuela, 1997, p. 107.
} 
suficientes para tratar determinadas situaciones que impactan igualmente a otros actores y territorios ${ }^{2}$. Por lo tanto, la gobernanza global se identifica como instrumento para facilitar las negociaciones, el alcance de consenso, la toma de decisiones y adopción de medidas eficaces que ayudan a ampliar ese espectro de actuación ${ }^{3}$.

Los procesos de gobernanza, que promueven la participación ampliada, se han mostrado cada vez más adecuados para enfrentar temas complejos que demandan cooperación entre actores diversos. Estos procesos pueden ser definidos e impulsados por Estados y Organizaciones Internacionales (Ols), bien que por actores no estatales que promuevan iniciativas e instrumentos normativos técnicos, que al cabo terminen por autorregular, aunque de forma voluntaria, prácticas y conductas que puedan afectar a otros actores. Estos instrumentos y herramientas, consideradas como soft law ${ }^{4}$, buscan atender a las expectativas de los denominados stakeholders 5 . En este sentido, en un primer momento, el presente estudio analiza el concepto de gobernanza global ${ }^{6}$ y la importancia del desarrollo de otras formas de gestión, que

\footnotetext{
${ }^{2}$ SAND, Peter H. The history and origin of international environmental law. Edward Elgar Pub. Limited, 2015, p. XIII.

${ }^{3}$ GONÇALVES, Alcindo. "Governança Global". In: GONÇALVES, Alcindo e COSTA, José Augusto Fontoura. Governança Global e Regimes Internacionais. São Paulo: Almedina, 2011, p. 83.

${ }^{4}$ Soft law generalmente es considerada como una especie de "norma social y no legal". (SHELTON, Dinah. "Soft law". In: Routledge handbook of international law. Routledge, 2009. pp. 99-111). Sin embargo, la principal característica que diferencia el soft law de las normas legales es su naturaleza no obligatoria. Las normas legales (hard law) poseen naturaleza jurídica vinculante y sancionadora, ya la soft law se caracteriza como una regla internacional de adopción voluntaria. (BEYERLIN, Ulrich; MARAUHN, Thilo. International Environmental Law. Oxford: Hart Publishing, 2011, p. 290). Por lo tanto, la soft law, a efectos de este estudio, se entiende como "conjuntos de reglas que tienen un carácter no vinculante, incluyendo no sólo conjuntos de principios y similares, sino también leyes modelo". DE CAROLIS, Daniele. "Some Features of the Harmonisation of International Trade Law in the Third Millennium". Unif. L. Rev., v. 15, p. 37, 2010).

${ }^{5}$ El término stakeholder acaba por tornarse una expresión frecuentemente utilizada para definir las partes o individuos interesados que influyen y/o son influenciados por las actividades y decisiones de una organización. (FREEMAN, R. Edward. "The stakeholder approach revisited". Zeitschrift für Wirtschafts-und Unternehmensethik, v. 5, n. 3, p. 228-254, 2004). El interés, en este caso, es relacionado con la organización, su entorno, los grupos de los cuales la organización necesita de apoyo para existir (inversores y accionistas), cualquier parte o individuo que pueda afectar o ser afectado por sus actividades y todos aquellos, por los cuales, la organización tenga obligaciones morales (NAVARRO GARCÍA, Fernando. Responsabilidad social corporativa: teoría y práctica. ESIC editorial, 2012, p. 73). La norma ISO 26000: Guía de responsabilidad social presenta la traducción del termo stakeholder como partes interesadas, que, por su vez, son definidas como "individuo o grupo que tiene interés en cualquier decisión o actividad de la organización" (ISO. International Organization for Standardization ISO. ISO 26000:2010(es)-Guia de responsabilidad social. Disponible en: $<$ https://www.iso.org/obp/ui\#iso:std:iso:26000:ed-1:v1:es>. Fecha de consulta: 02/12/201).

${ }^{6} \mathrm{La}$ Gobernanza Global surge como consecuencia de la globalización, debido a los diversos cambios traídos a las relaciones entre sociedad y Estado proporcionando la reconfiguración del papel de estos actores ante los desafíos sociales. La gobernanza global tiene carácter instrumental, pues, propicia la participación ampliada de múltiples actores, estatales y no estatales, en la búsqueda de consensos que generalmente se alcanzan a través de la persuasión y negociación para la institucionalización de normas, principios y reglas. (GONÇALVES, Alcindo, op. cit., pp. 53-54).
} 
permitan la definición de herramientas técnicas para tratar las cuestiones socioambientales.

En seguida, analiza el contexto de la Responsabilidad Social Corporativa (RSC) ${ }^{7}$ y su dinámica actual frente a las demandas sociales, económicas y medioambientales, para demostrar la importancia de las normas técnicas en un contexto de regulación y autorregulación ${ }^{8}$ de las actividades empresariales, en el escenario internacional. Además, busca explicar cómo instrumentos normativos técnicos y voluntarios son capaces de incluir a las organizaciones privadas en las agendas internacionales, encaminar los temas comunes e, incluso, influir en la ley estatal ${ }^{9}$. Con ello, la idea es presentar el contexto de la creciente demanda por la implementación de políticas y prácticas que atiendan a los objetivos de las organizaciones, sus compromisos, las exigencias legales y expectativas de las partes interesadas. Lo que comprende, la creciente actividad de autorregulación por la necesidad de generar eficiencia y resultados efectivos para los problemas socioambientales y el desarrollo sostenible.

Por tanto, el reto principal de este estudio es identificar las razones por las cuales estos instrumentos son capaces de direccionar, aunque de forma indirecta (no directamente obligatoria), la adopción de determinadas prácticas en las organizaciones privadas, esto es, comprender como la autorregulación es capaz de fomentar la conformidad empresarial, a partir de las demandas globales y contribuir para el encaminamiento de las cuestiones socioambientales.

\footnotetext{
${ }^{7}$ La Norma Técnica ISO 26000: Orientación sobre Responsabilidad Social - define responsabilidad social como la "responsabilidad de una organización por los impactos de sus decisiones y actividades en la sociedad y en el medio ambiente". De acuerdo con la norma, la Responsabilidad Social Corporativa (RSC) debe ser demostrada a través de prácticas transparentes y éticas que puedan contribuir a la sociedad y el desarrollo sostenible, considerando, sobre todo, la legislación aplicable y las expectativas de las partes interesadas". (ABNT. Associação Brasileira De Normas Técnicas. NBR ISO 26000: Diretrizes sobre responsabilidade social. Rio de Janeiro: ABNT, 2010.

${ }^{8}$ Las nociones de regulación y Estado y autorregulación y sociedad son necesarias para la comprensión de los términos. La regulación es asociada a la intervención del Estado, a través de la administración pública, en la gestión de determinados temas. La autorregulación, por su vez, es de origen social y está relacionada con la actividad social de producción normativa y de reglamentos privados (DARNACULLETA I DARNACULLETA I GARDELLA, Mercé. Derecho Administrativo y Autorregulación: La Autorregulación regulada. (Tesis Doctoral). Girona: Universidad de Girona. Departamento de Derecho Público. 2002, p. 15). En el contexto de la RSC, la autorregulación es concepto que define la capacidad que determinada empresa o segmento posee para gestionar un tema y/o proceso. Es la capacidad de analizar un determinado entorno o contexto con el reto de solucionar, mejorar o mitigar el problema que se pretende enfrentar, a través de la definición de objetivos, principios, normas y herramientas de naturaleza voluntaria (DOPAZO FRAGUÍO, Pilar. "La responsabilidad social corporativa (RSC)", op. cit.).

${ }^{9}$ GEIGEL, Nelson, op. cit., p.107.
} 


\section{GOBERNANZA SOCIOAMBIENTAL GLOBAL}

La gobernanza global es un término empleado para definir un conjunto complejo de estructuras y procesos, tanto públicos como privados, con fines de concretar estrategias para la toma de decisione ${ }^{10}$. Es un concepto que define la "totalidad de las diversas formas en que individuos e instituciones, públicas o privadas, manejan sus problemas comunes"11.

La gobernanza global, consecuentemente, es un medio o proceso en el cual participan diferentes actores estatales y no estatales, para intervenir en cuestiones y obtener consensos que culminan en procedimientos, normas y herramientas que viabilicen las decisiones tomadas entre los actores involucrados ${ }^{12}$. La gobernanza global puede estar caracterizada como un ejercicio de diálogo y de toma de decisiones multinivel ${ }^{13}$, que define políticas y mecanismos para el enfrentamiento de una determinada cuestión.

Son elementos importantes de la gobernanza: la participación ampliada, la cooperación y la obtención de consensos, para la búsqueda de soluciones y resultados eficaces para los problemas globales ${ }^{14}$. Se podría decir, entonces, que la gobernanza global es un medio con capacidad de acción colectiva, que promueve la cooperación internacional, para abordar cuestiones políticas, económicas, sociales y medioambientales, que son prioridades en el escenario mundial. Se trata de un proceso que busca la participación dinámica y ampliada de múltiples actores para la toma de decisiones conjuntas y descentralizadas, sobre propuestas de formulación de instrumentos y herramientas que, independientemente de su naturaleza jurídica, buscan legitimar el proceso de diálogo y de toma de decisiones establecido.

Es cierto que los Estados ejercen el protagonismo ${ }^{15}$ en la solución de los asuntos internacionales. Su papel regulador es crucial para garantizar el orden y la conducta en importantes escenarios. Sin embargo, los procesos de diálogo y acción que se

\footnotetext{
${ }^{10}$ WEISS, Thomas. "Governance, good governance and global governance: conceptual and actual challenges". Third world quarterly, v. 21, n. 5, pp. 795-814, 2000.

${ }^{11}$ CMMAD. Comissão Mundial sobre Meio Ambiente e Desenvolvimento. Nosso futuro comum. Rio de Janeiro: Editora da Fundação Getúlio Vargas, 1991, p. 02.

${ }^{12}$ GONÇALVES, Alcindo, op. cit., p. 83.

${ }^{13}$ KINGSBURY, Benedict; KRISCH, Nico; STEWART, Richard. "The emergence of global administrative law". Law and contemporary problems, v. 68, n. 3/4, pp. 15-61, 2005.

${ }^{14}$ GONÇALVES, Alcindo, op. cit., p.53.

${ }^{15}$ CMMAD. Comissão Mundial sobre Meio Ambiente e Desenvolvimento, op. cit., p. 08.
} 
establecen en el contexto de la gobernanza también pueden ser iniciados, definidos y desarrollados, en parte o en su totalidad, por otros entes, o sea por actores privados. Además, la gobernanza global implica la superación del modelo de gestión vertical y vinculante, donde el sistema de toma de decisiones bottom-up parece ser que se adecua mejor ${ }^{16}$. Es que este sistema se caracteriza por la presencia de una producción normativa voluntaria, sin actos de gobierno impuestos a partir de instancias centrales de modo vertical ${ }^{17}$. La gobernanza, por lo tanto, se establece en un escenario que privilegia la interacción de diversos actores afectados y/o interesados en el establecimiento de pautas de interés común, a ser implementadas a nivel global.

En el actual contexto del mundo globalizado, se abrieron fronteras y un espacio irreversible sobre la actuación de actores no estatales en el escenario internacional, como empresas, trabajadores y organizaciones no gubernamentales (ONGs) ${ }^{18}$. El ascenso de la gobernanza socioambiental global se torna, consecuentemente, una vía posible para enfrentar y reducir los problemas económicos, culturales, sociales y ecológicos oriundos de la globalización, creando nuevas relaciones y permitiendo "una creciente institucionalización del proceso de decisión más allá de los límites del Estado-nación"19 , demandando, sobretodo, mayor cooperación y diálogo para el logro de buenos resultados. La colaboración entre las partes interesadas y el establecimiento de consensos para tratar asuntos socioambientales son capaces de suplantar lagunas legales existentes en políticas estatales. Al que parece ser el caso de la Responsabilidad Social Corporativa (RSC).

\footnotetext{
${ }^{16}$ KINGSBURY, Benedict; KRISCH, Nico; STEWART, Richard, op. cit.

${ }^{17}$ VILLAS BÔAS FILHO, Orlando. "As transformações da regulação jurídica na sociedade contemporânea: a governança como paradigma". Revista Direito GV, [S.1.], v. 12, n. 1, pp. 251-259, fev. 2016. ISSN 2317-6172. Disponible en: <http://bibliotecadigital.fgv.br/ojs/index.php/revdireitogv/article/view/59462/57853>. Fecha de consulta: 22/11/2018.

${ }^{18}$ Las ONGIs (Organizaciones No Gubernamentales Internacionales) son personas jurídicas de derecho privado e interno, sin fines de lucro. Son organizaciones que surgen de intereses públicos y objetivos comunes como derechos humanos, salud, educación, medio ambiente y consumo. Debido a su papel crítico y representativo de actuación en la defensa de la sociedad, las ONGIs han sido reconocidas como "socios" del sistema de las Naciones Unidas, especialmente en negociaciones, demostrando ser "esenciales para la formación de una especie de conciencia global en el enfrentamiento de determinados problemas de la humanidad". (MATIAS, Eduardo Felipe. A humanidade e suas fronteiras: do Estado soberano à sociedade global. Editora Paz e Terra, 2015, p. 447).

${ }^{19}$ BIERMANN, Frank. "Global Environmental Governance. Conceptualization and Examples". Global Governance Working Paper No 12. Amsterdam, Berlin, Oldenburg, Potsdam: The Global Governance Project, 2004. Disponible en:<www.glogov.org $>$. Fecha de consulta: 24/09/2018.
} 
La gobernanza socioambiental se convierte en "un instrumento de participación en la toma de decisiones más complejas (públicas y privadas) y en todos los niveles, de lo global a lo local"20 y se identifica como un mecanismo que, para funcionar con eficacia, necesita principalmente la participación y actuación efectiva de determinados actores, como en el caso de las organizaciones privadas. La participación de estos actores ha sido de extrema relevancia, pues la responsabilidad de las empresas se ha vuelto cada vez más compleja, precisamente porque las empresas se insertan de manera expedita en el contexto del mercado transnacional, alcanzando y quizá afectando diversas regiones y públicos simultáneamente ${ }^{21}$.

Por otro lado, debido a cuestiones económicas y de soberanía, se hizo igualmente complejo para los Estados la reglamentación de las actividades empresariales, a través de normativas internas o incluso por acuerdos multilaterales ${ }^{22}$. Por esa razón, se identifica un vacío en la reglamentación jurídica internacional, que permita el control efectivo de las prácticas empresariales transnacionales, que depende de innumerables factores y convergencias de intenciones entre los actores implicados.

La Organización de las Naciones Unidas (ONU) ha buscado un camino común para enfrentar esta cuestión. La Resolución A/HRC/RES/26/9 del Consejo de Derechos Humanos de las Naciones Unidas, de 26 de junio de $2014^{23}$, presenta la propuesta de un tratado internacional vinculante para regular las acciones de las empresas transnacionales y sus cadenas de suministros en lo que respecta a los derechos humanos.

De esta propuesta se han reflejado otros trabajos, que incorporan los objetivos de la ONU de controlar las acciones de las empresas y poner fin al vacío jurídico identificado. Un importante ejemplo es la Propuesta de Resolución $(2018 / 2763(\text { RSP }))^{24}$ del Parlamento Europeo sobre las actividades de las empresas

\footnotetext{
${ }^{20}$ VILLAS BÔAS FILHO, Orlando, op. cit.

${ }^{21}$ LIMA, Luciana; REI, Fernando. "O Papel da Soft Law privada no Enfrentamento da Problemática Socioambiental Global”. Revista Eletrônica Direito e Política, v. 13, n. 2, pp. 855-879, 2018.

${ }^{22}$ Ibídem.

${ }^{23}$ La Resolución A/HRC/RES/26/9 el Consejo de Derechos Humanos das Naciones Unidas, de 26 de junio de 2014 propone la elaboración de un instrumento jurídicamente vinculante sobre la responsabilidad de las empresas transnacionales y otras empresas con respecto a los derechos humanos. (Resolución A/HRC/RES/26/9 del Consejo de Derechos Humanos das Naciones Unidas, de 26 de junio de 2014 - Elaboración de un instrumento jurídicamente vinculante sobre la responsabilidad de las empresas transnacionales y otras empresas con respecto a los derechos humanos. Disponible en: $<$ http://www.ccoo.es/8f72c6f049f78e3171882d193b0b31b3000001.pdf $>$. Fecha de consulta: 22/01/2019).

${ }^{24}$ Vid. Resolución del Parlamento Europeo sobre la contribución de la Unión a un instrumento vinculante de las Naciones Unidas sobre las empresas transnacionales y otras empresas con características transnacionales con
} 
transnacionales. La Resolución del Parlamento Europeo surge como respuesta y apoyo de la Unión Europea a la Resolución A/HRC/RES/26/9 del Consejo de Derechos Humanos de las Naciones Unidas. La propuesta resalta aún en su texto, la importancia de que haya una coordinación efectiva, para que el mayor número posible de naciones ratifiquen el tratado internacional vinculante, de forma que se garantice que el instrumento sea efectivo a nivel global.

Sin embargo, ya existe en el contexto Europeo una normativa que trata de la responsabilidad de las empresas transnacionales sobre los temas socioambientales. La Directiva 2014/95/UE del Parlamento Europeo y del Consejo, de 22 de octubre de 2014, que modifica la directiva 2013/34/UE referente a la "divulgación de información no financiera e información sobre diversidad por parte de determinadas grandes empresas y determinados grupos" 25 , tiene como objetivo controlar las actividades de las empresas que operan en su territorio o que le suministran productos y servicios. Esta directiva busca obligar a las empresas a ajustarse en los requisitos de la norma y a informar sobre los factores sociales y medioambientales de sus actividades con el propósito de mejorar la sostenibilidad y la confianza de los inversores, de los consumidores y de la sociedad en general.

La Directiva 2014/95/UE ha reflejado recientemente la transposición de sus comandos en el ordenamiento jurídico interno de España, a través de la Ley 11/2018, de 28 de diciembre de 2018, "por la que modifica el Código de Comercio, el texto refundido de la Ley de Sociedades de Capital aprobado por el Real Decreto Legislativo 1/2010, de 2 de julio, y la Ley 22/2015, de 20 de julio, de información no financiera y diversidad"26. La referida Ley regula la obligación de información de RSC por parte de las empresas de España, que ahora están obligadas a presentar informes no financieros sobre materia social y medioambiental.

\footnotetext{
respecto a los derechos humanos (2018/2763(RSP)). Disponible en: $<$ http://www.europarl.europa.eu/sides/getDoc.do?pubRef=-//EP//NONSGML+MOTION+B8-20180472+0+DOC+PDF+V0//ES >. Fecha de consulta: 10/02/2019.

${ }^{25}$ La Directiva 2014/95/EU del Parlamento Europeo y del Consejo de 22 de octubre de 2014 es una norma que establece reglas rígidas sobre la divulgación de informes de grandes empresas referentes al impacto de sus actividades sobre las cuestiones ambientales, de trabajo decente, bien como de lucha contra la corrupción y respeto a los derechos humanos. (DOUE L 330/1, de 2014). Disponible en: $<$ https://www.boe.es/buscar/doc.php?id=DOUE-L-2014-83373 >. Fecha de consulta: 12/01/2019.

${ }^{26}$ Vid. BOE-A-2018-17989: https://www.boe.es/buscar/doc.php?id=BOE-A-2018-17989.
} 
Sin embargo, a pesar de haber un impulso regulatorio en este sentido, la realidad es que el alcance de estas normas es limitado, debido a la dinámica comercial global que se expande rápidamente, tornando dificultoso el control de forma individual o unilateral. Por otro lado, hay normas que ya poseen un cierto componente de extraterritorialidad y que definen la responsabilidad de empresas que actúan dentro o fuera de los territorios nacionales y que mantienen relaciones con el país emisor de la ley $^{27}$. Este es el caso de la norma americana, Foreign Corrupt Practices Act (FCPA) ${ }^{28}$ y inglesa The Bribery Act de $2010^{29}$ sobre soborno y corrupción, bien como de la Ley Orgánica española 5/2010, de 22 de junio ${ }^{30}$ de 2010, por la que se modifica la Ley Orgánica 10/1995, de 23 de noviembre de 1995, del Código Penal. El artículo 31 del referido Código prevé, entre otros delitos, la responsabilidad penal de la persona jurídica que esté involucrada con crímenes contra los recursos naturales y medioambientales, así como de corrupción y soborno en las transacciones comerciales internacionales. El alcance de esta norma también es extraterritorial, ya que las empresas son responsables por los delitos cometidos aunque no estén en territorio español, es decir, para que una empresa responda por los delitos, basta que tenga sede social en España o que haga negocios (incluso en pequeña parte) en territorio español. La ley alcanzará incluso fuera del país a las empresas, sus directivos y a los demás empleados. Así, las personas jurídicas, que se encajen en los requisitos de la norma española, serán responsables por los crímenes cometidos en su nombre o por su cuenta, en beneficio directo o indirecto, desde que no haya sobre ellos el debido control. El rigor de la ley presenta todavía la posibilidad de acumulación de

\footnotetext{
${ }^{27}$ LEIBOLD, Annalisa. "Extraterritorial Application of the FCPA Under International Law". Willamette L. Rev., v. 51 , p. $225,2014$.

${ }^{28} \mathrm{La}$ ley FCPA prohíbe prácticas de soborno por parte de las compañías de Estados Unidos y sus subsidiarias, independientemente dónde operen o estén ubicadas. Por lo tanto, a FCPA se aplica a cualquier persona que tenga relaciones o conexiones con los Estados Unidos y incumpla las reglas de la norma, mismo que no esté presente físicamente en el territorio americano. El incumplimiento de la norma puede acarrear además de las cuantiosas multas, daños a la reputación e imagen, largos y costosos procesos judiciales e impedimento de llevar a cabo operaciones y negocios importantes para las organizaciones. (Ibídem).

${ }^{29}$ La ley The The Bribery Act del Reino Unido establece la responsabilidad de las empresas en la prevención del soborno. Así, de acuerdo con la norma, empresas con sede o no en el Reino Unido serán responsables por actos de soborno, independientemente de donde se produzcan. La ley considera todavía que esta responsabilidad involucra las actuaciones en nombre y/o en provecho de la empresa, mismo que estas acciones se produzcan sin su conocimiento. (BOISTER, Neil. An introduction to transnational criminal law. Oxford University Press, 2012, pp. 96-97).

${ }^{30}$ Vid. Documento/texto legal consolidado, Ley orgánica 5/2010, de 22 de junio (OE-A-2010-9953). Disponible en: $<$ https://www.boe.es/eli/es/lo/2010/06/22/5>. Fecha de consulta: 10/01/2019.
} 
responsabilidades entre persona física y jurídica, o sea, en la comisión de un delito, pueden responder tanto la persona física como la jurídica, incluso simultáneamente ${ }^{31}$.

El control de las actividades empresariales no es una práctica completamente difundida o bien desarrollada por todos los países, lo que perjudica la obtención de una uniformidad global en la gestión de las prácticas de las empresas transnacionales, hecho que puede generar un cierto grado de dificultad de actuación para algunas organizaciones y para otras no. Además, el alcance de las leyes nacionales y/o supranacionales, aún presentan problemas de efectividad, por razón de soberanía y de control de las actividades extraterritoriales ${ }^{32}$. En este sentido, el objetivo de encontrar un medio de acción global y coordinado, para enfrentar un problema tan complejo, es importante para disminuir contrastes en las sanciones por incumplimiento de las reglas e impedir tratamientos diferenciados, que puedan permitir prácticas de explotación indebida de recursos naturales y que violen normas internacionales, tanto de derechos humanos como ambientales ${ }^{33}$.

Frente a ello, surgen sistemas más amplios de gobernanza, que posibilitan la actuación de múltiples actores en el escenario internacional como forma de disminuir este vacío legal y contribuir de forma más efectiva para el logro de resultados positivos. Esta dinámica de enfrentamiento de conflictos permite un cambio en las relaciones internacionales al descentralizar la actuación, antes exclusiva de los Estados $^{34}$, admitiendo el intercambio de conocimientos, herramientas y acciones entre diferentes actores, para enfrentar temas más complejos. Participar en el proceso de gobernanza global permite al sector privado gestionar e incrementar buenas prácticas, a través del desarrollo de políticas de actuación que proporcionan una mirada más cuidadosa y responsable con asuntos que son inherentes a su propio desarrollo y permanencia en ese contexto.

Las empresas de hoy poseen un papel importante en el contexto global. Son actores de gran relevancia e indispensables para el mantenimiento de algunas comunidades y agendas internacionales. Sin embargo, este proceso no puede ser analizado sólo bajo el aspecto de los beneficios económicos. Las empresas poseen

\footnotetext{
${ }^{31}$ BARRANCO, Mata et al. Derecho penal económico y de la empresa. Madrid: Editorial Dykinson, 2018, p. 444.

${ }^{32}$ KINGSBURY, Benedict; KRISCH, Nico; STEWART, Richard, op. cit.

${ }^{33}$ LIMA, Luciana; REI, Fernando, op. cit.

${ }^{34}$ MATIAS, Eduardo Felipe, op. cit., p. 445.
} 
responsabilidades ante su público interno y externo, que involucra a los empleados, accionistas, gobiernos, consumidores y a la sociedad en general. Un ejemplo: de acuerdo con los principios de derechos humanos, las empresas deben, en su ámbito de influencia, apoyar y respetar la protección de los derechos proclamados internacionalmente, así como asegurarse de que no son cómplices de violaciones ${ }^{35}$.

El compromiso con la ética, transparencia, respeto a los derechos humanos y al medioambiente son prácticas importantes para la organización, contribuyendo, incluso, a la mejora de su desempeño económico. Además, producen una buena imagen ante las partes interesadas, porque demuestran el empeño de la organización con el atendimiento de las diversas expectativas que, en gran medida, están relacionadas con los principales comandos internacionales y legales sobre la reducción de conflictos sociales y problemas ambientales ${ }^{36}$.

La participación de las empresas en este contexto se debe, igualmente, a la necesidad de defender sus propios intereses, ya que son directamente afectadas por las demandas sociales y comerciales que, por su turno, generan regulación socioambiental ${ }^{37}$. Por otro lado, su participación en la gobernanza global es importante por ser el grupo que llevará a cabo la implementación práctica de las decisiones tomadas en el proceso.

\section{LA SOFT LAW EN EL CONTEXTO DE LA RESPONSABILIDAD SOCIOAMBIENTAL CORPORATIVA}

El fundamento de la Responsabilidad Social Corporativa (RSC) es de origen voluntario. Sin embargo, los debates sobre cuáles son las responsabilidades que las empresas deben asumir, además de sus obligaciones legales, incorporan las teorías

\footnotetext{
${ }^{35}$ UN. United Nations. Guide, An Interpretive. The corporate responsibility to respect human rights, 2012 , p.48. Disponible en: <https://www.ohchr.org/Documents/Publications/HR.PUB.12.2_En.pdf $>$. Fecha de consulta: $15 / 11 / 2018$.

${ }^{36} \mathrm{UN}$. United Nations. Guide, An Interpretive. The corporate responsibility to respect human rights, 2012 , p.55. Disponible en: <https:/www.ohchr.org/Documents/Publications/HR.PUB.12.2_En.pdf >. Fecha de consulta: 15/11/2018.

${ }^{37}$ SILVEIRA ANDRADE, Jose Célio. "Participação do setor privado na governança ambiental global: Evolução, contribuições e obstáculos”. Contexto Internacional, v. 31, n”. 2, 2009.
} 
sobre los deberes de cumplimiento y de informes ${ }^{38}$ necesarios para atender, igualmente, las expectativas de las partes interesadas.

Es cierto que la función principal de una organización es mantenerse en el mercado, aumentar su valor y satisfacer los intereses de los stakeholders ${ }^{39}$. Sin embargo, las partes interesadas no se limitan a los accionistas e inversores. Estos grupos también están formados por consumidores, clientes, trabajadores, otras empresas, ONGs, gobiernos y organismos reguladores, es decir, por todos aquellos que, por cualquier razón, estén impactados o interesados por las actividades de la organización y que también puedan implicar en la perennidad del negocio.

El concepto de RSC actualmente ha sido definido como la decisión que una organización toma sobre su forma de actuar ante determinadas cuestiones sociales y/o ambientales, a fin de atender a las expectativas de los stakeholders. Esta decisión sobre la actuación empresarial se convierte en compromisos asumidos y declarados públicamente y que se materializan en un programa de acción propio, el cual lleva "a la realización de prácticas concretas congruentes con los principios internacionales de RSC"40. Por otro lado, el impacto producido por determinada parte interesada puede llevar a pérdidas tangibles y/o intangibles, y, consecuentemente, a disminuciones en el valor de mercado de una organización. Además, algunos inversores, "cada vez más interesados en las actividades de las corporaciones que, indiscutiblemente, se extienden más allá de simplemente maximizar la riqueza"41, han observado a las políticas ambientales, sociales y de gobernanza (ESG) ${ }^{42}$ como criterio para toma de decisiones.

\footnotetext{
${ }^{38}$ Los informes esperados de una organización (Reporting Corporate), en el contexto de la RSC están relacionados al sistema de gobernanza adoptado y a la gestión integrada de la responsabilidad social y medioambiental a que se propone realizar, cumpliendo los objetivos definidos y asumidos como estrategia organizacional. La información, documentalmente declarada por una organización, debe estar en conformidad con la actuación diligente y remeter a prácticas sostenibles sobre los aspectos que busca informar, es decir, deben ser informaciones precisas, efectivas, gestionadas y revisadas periódicamente, pues, los informes configuran una importante fuente de conocimiento acerca de la organización, así como revela su cultura corporativa. (DOPAZO FRAGUÍO, Pilar. "Informes de responsabilidad social corporativa (RSC): fuentes de información y documentación". Revista general de información y documentación, v. 22, pp. 279-305, 2012).

${ }^{39}$ CARROLL, Archie. "A three-dimensional conceptual model of corporate performance". Academy of management review, v. 4, n. 4, p. 497-505, 1979.

${ }^{40}$ DOPAZO FRAGUÍO, Pilar. Informes..., op. cit.

${ }^{41}$ GILLAN, Stuart et al. "Firms' environmental, social and governance (ESG) choices, performance and managerial motivation". Unpublished working paper, 2010.

${ }^{42}$ ESG, por su sigla en inglés de Environmental, Social and Governance, son criterios de inversiones relacionados a factores medioambientales, sociales y gobernanza corporativa, definidos para ayudar a los inversores na toma de decisiones. Estos criterios son estructurados y alineados para permitir mayor y mejor conocimiento y gestión de
} 
No obstante, para atender a los diversos intereses, las empresas necesitan comprobar el cumplimiento de las normas nacionales, supranacionales y/o internacionales, pero, también, demonstrar la adopción de prácticas sostenibles en todo su proceso de gestión, incluido el control de insumos y proveedores. Esto ocurre porque las responsabilidades de las empresas se extienden más allá de sus muros ${ }^{43}$, influenciando e impactando a las personas y comunidades del entorno y otros actores importantes para el negocio. Estos criterios se amplían, sobre todo, a las organizaciones que expanden sus actividades más allá de las fronteras de un determinado país o región, volviéndose transnacionales, porque llevan su influencia hacia otros espacios, aumentando aún más el área de impacto.

Frente a la interrelación y complejidad de los problemas socioambientales, se entiende que la RSC ha obtenido mayor interés y centralidad ante los desafíos de gestión e integración global sobre los controles de riesgos e impactos de las operaciones empresariales transnacionales. Por eso, el compromiso hacia la RSC incluye, además de la participación de la organización en el proceso de gobernanza, un cambio en la cultura organizacional para desenvolver estrategias de gestión que permitan el avance de prácticas eficientes relacionadas con la transparencia y rendición de cuentas (control público), así como con el compromiso ético, participación y dialogo con las partes interesadas ${ }^{44}$, hecho que acaba por definir los principios de "buen gobierno corporativo"45, que a su vez, lleva en cuenta las obligaciones de informes y controles sobre los criterios ESG.

Se puede decir por tanto que la buena gobernanza es caracterizada por la "participación, el consenso orientado, responsable, transparente, eficaz y eficiente,

\footnotetext{
los riesgos y proporcionar la toma de decisión sobre inversiones más responsables y sostenibles. (GSIA. Global Sustainable Investment Alliance. Global Sustainable Investment Review, 2016. Disponible en: < http://www.gsialliance.org/wp-content/uploads/2017/03/GSIR_Review2016.F.pdf >. Fecha de consulta 15/01/2019).

${ }^{43}$ CARROLL, Archie. "A three-dimensional conceptual model of corporate performance". Academy of management review, v. 4, n. 4, pp. 497-505, 1979.

${ }^{44}$ DOPAZO FRAGUÍO, Pilar. Informes..., op. cit.

${ }^{45} \mathrm{El}$ concepto de gobierno corporativo está relacionado al modelo de gobernanza de una determinada una organización, es decir, la forma como la organización é dirigida y controlada. A partir de esto concepto, se comprende que "buen gobierno" es la calidad atribuida a la forma de gestión y control empleados. Estos controles involucran aspectos verificados y acreditados que buscan compraban que la organización posee un "óptimo grado de cumplimiento legal, $y$, además, informar sobre el cumplimiento efectivo del sistema de autorregulación, que hubiera adoptado de forma voluntaria (integrando aspectos relativos a RSC / RSE) y previa evaluación de su funcionamiento". (DOPAZO FRAGUÍO, Pilar. "La responsabilidad social corporativa (RSC) como activo facilitador de la innovación jurídica". REJIE: Revista Jurídica de Investigación e Innovación Educativa, n. 13, pp. 31-48, 2016).
} 
equitativo e inclusivo y sigue el estado de derecho"46. La buena gobernanza tiene un sentido de acción positiva, de logro de objetivos y compromisos. El acto de gobernar está asociado a la transparencia, a la ética y a la responsabilidad socioambiental. Así que el concepto de la RSC se fundamenta en la necesidad de que las organizaciones adopten una "estratégica adecuada, que facilite el cumplimiento de las obligaciones jurídicas prescritas y los propios compromisos voluntariamente asumidos" 47 , pues, la demanda actual sobre la actuación responsable de las organizaciones incluye, además de la conformidad legal, el compromiso con sus propias políticas, directrices, estándares y con el desarrollo sostenible.

El desarrollo sostenible ha sido un gran desafío para las empresas, teniendo en cuenta que sus elementos estructurales están interrelacionados y son interdependientes. El "trípode de la sostenibilidad"48, compuesto por las dimensiones ambiental, social y económica, es una concepción que busca ampliar la mirada sobre la necesidad de equilibrio y equidad sobre el desarrollo. La sostenibilidad del negocio está íntimamente enlazada a la actuación diligente de la empresa en el ejercicio de sus actividades, que posee el objetivo de lograr un triple resultado positivo, es decir, resultados basados en la gestión de los riesgos económicos, sociales y ambientales ${ }^{49}$. Esta realidad exige que haya una estrategia bien definida y criterios de actuación que puedan permitir la atención a las demandas, y, sobre todo, "garantizar su crecimiento y competitividad"50. Para adecuarse a este escenario, las empresas necesitan instrumentos que ayuden en la adopción de prácticas y formas de gestión, que permitan un mejor y más efectivo control interno ${ }^{51}$. Estos controles son capaces de proteger activos y valores de

\footnotetext{
${ }^{46}$ UNESCAP. United Nations Economic and Social Commission for Asia and the Pacific. What is Good Governance? Disponible en: $<$ https://www.unescap.org/sites/default/files/good-governance.pdf $>$. Fecha de consulta: 20/11/2018.

${ }^{47}$ DOPAZO FRAGUÍO, Pilar. "Responsabilidad Empresarial por Riesgos Ambientales en España: Implicaciones Jurídicas y Estratégicas”. Revista de Estudos Jurídicos UNESP, v. 14, n. 20, 2011.

${ }^{48}$ Triple Bottom Line (TBM) o People, Planet, Profit (PPP) se refiere al concepto empleado a la forma de incorporación de la gestión empresarial en la agenda de desarrollo sostenible, considerando un resultado que involucra los aspectos económicos, medioambientales y justicia social. (ELKINGTON, John. Canibais com garfo e faca: seria um sinal de progresso se um canibal utilizasse garfo e faca para comer? São Paulo: Makron Books, 2001, p.12).

${ }^{49}$ RUGGIE, John Gerard. Quando os Negócios não são Apenas Negócios: as Corporações Multinacionais e os Direitos Humanos. São Paulo: Editora Planeta Sustentável, 2014, p.13.

${ }^{50}$ DOPAZO FRAGUÍO, Pilar. Responsabilidad..., op. cit.

${ }^{51} \mathrm{El}$ control interno es una práctica de gestión difundida actualmente no medio empresarial situándose en el marco de la gerencia corporativa, con la función de identificar, analizar y tratar los riesgos de la actividad, definir responsabilidades, supervisar conductas y evaluar resultados. Sobre el control interno aún no existe un régimen jurídico definido, pero es un concepto soportado por modelos normalizados de grande relevancia en el mercado. (TEI-
} 
mercado ante riesgos y posibles situaciones de no conformidad, tanto legal como de sus propios objetivos, políticas, códigos de conducta y otras normas voluntarias, a menudo utilizadas por el mercado y asumidas por las organizaciones. Los controles internos, generalmente basados en estándares técnicos de adopción voluntaria, permiten demostrar la prevención de riesgos, la proactividad y el interés en su tratamiento, y, sobre todo, la conformidad consonante "a requerimientos técnicos, jurídicos y económicos-financieros, entre otros posibles"52. Además, estos controles son capaces de ostentar una buena gobernanza corporativa, a través del ánimo de la organización ante las demandas y su capacidad de respuesta a los riesgos ${ }^{53}$.

La gobernanza corporativa en el contexto de la RSC integra o comprende dos vertientes: la regulatoria (obligatoria) y la autorregulatoria (voluntaria). La primera, compuesta por las normas legales que son impuestas a las organizaciones y que necesariamente deben ser cumplidas. Por su turno, la autorregulatoria es parte de la gobernanza realizada por el ánimo voluntario de la organización, o sea, la organización decide adoptar en su sistema de gestión, normas no legales ${ }^{54}$, impulsadas por el contexto global y por demanda de las partes interesadas, que buscan ir más allá de las obligaciones legales. Esta parte está involucrada por un conjunto de reglas y prácticas asumidas por la alta dirección de la organización que informa a su vez a todos interesados su compromiso y responsabilidad con una gestión más ampliada para atender a las exigencias que van más allá de las legales.

Las expectativas de las diferentes partes interesadas pueden coincidir, pero, no es necesariamente así. Sobre el cumplimiento legal, se puede decir que es una de las expectativas de todos los stakeholders, pues, deriva de obligaciones que deben ser imperiosamente cumplidas. Sin embargo, las expectativas relacionadas a la RSC, como se ha apuntado anteriormente, van más allá y esperan que la organización demuestre compromiso con otros valores económicos, sociales, éticos y morales, que pueden no estar suscritos en leyes. Por eso, existe la necesidad de soporte y complementariedad técnica, que puedan ayudar a las organizaciones a demonstrar

JEIRA RODRÍGUEZ, Mariano. "Responsabilidad social corporativa y compliance legal (autorregulación y control interno)". In: Derecho administrativo del medio ambiente: Temas y prácticas de actualidad jurídica. Servicio de Publicaciones de la Facultad de Derecho, 2018. p. 224).

${ }^{52}$ TEIJEIRA RODRÍGUEZ, Mariano, op. cit.

${ }^{53}$ DOPAZO FRAGUÍO, Pilar. La responsabilidad..., op. cit.

${ }^{54}$ ANAD, Anita. "Voluntary vs Mandatory Corporate Governance: Towards an Optimal Regulatory Framework", American Law \& Economics Association Annual Meetings, n.44, 2005. 
su responsabilidad en todos los ámbitos. Para atender a esta demanda y contribuir para el desarrollo, surgen herramientas como estándares técnicos, que se traducen en recomendaciones, directrices y requisitos privados que posibilitan el encaminamiento de las cuestiones socioambientales. Estos instrumentos técnicos, considerados como soft law ${ }^{55}$, por referirse a una especie de norma social voluntaria, que posee principios, directrices y declaraciones referentes a un determinado comportamiento esperado ${ }^{56}$, son capaces de influenciar, dar soporte y direccionar las prácticas de las organizaciones aunque de forma indirecta.

Las normas técnicas específicamente, son instrumentos soft law por su naturaleza voluntaria y no vinculante. En general, son instrumentos internacionales, que poseen directrices, requisitos o recomendaciones aceptadas y asumidas por las organizaciones. Algunas de ellas, crean sistemas de gestión certificables en temas como medioambiente, calidad de productos y servicios, corrupción y soborno. En el contexto de la RSC estas normas con características de soft law se han multiplicado justamente por adecuarse a las peculiaridades y dinámica de la RSC, donde la obligatoriedad y coerción son más difíciles de establecer. Luego, la importancia del uso de normas técnicas suele estar reflejada por la necesidad de atender a los intereses de los stakeholders, por la posibilidad de sufrir sanciones derivadas del incumplimiento de otras normas obligatorias (hard law), y, todavía, con base en la consideración del valor de reputación y de influencias, que llevan a su efectivo cumplimiento. Además, adoptar estándares y demostrar adecuación a legislaciones y normas, puede generar "ventaja competitiva global cuando otros países adopten más adelante esas normas" 57 ,

\footnotetext{
${ }^{55}$ Soft law es un término general, que involucra una serie de definiciones y discusiones sobre la naturaleza jurídica de normas de adopción voluntaria, todavía, para efecto de este estudio, el análisis de las normas soft law no se preocupa con esta discusión, pero sí, con las características que incluyen esta especie normativa en una condición e importancia para el análisis de la gobernanza socioambiental global y de la RSC. La adecuación y aplicación de normas soft law en sistemas de reglamentación más complejos, donde la normativa legal demuestra la necesidad de complementariedad y flexibilidad, es la razón por la cual se busca estudiar y comparar este fenómeno normativo no vinculante. (FRIEDRICH, Jürgen. International Environmental "soft law": The Functions and Limits of Nonbinding Instruments in International Environmental Governance and Law. Springer Science \& Business Media, 2013, p.19). La mayor flexibilidad de estos instrumentos permite, incluso, que sean herramientas importantes para la aplicación y concretización de sistemas legales. (TRUBEK, David M.; COTTRELL, M. Patrick; NANCE, Mark. "Soft Law, "Hard Law,' and European Integration: Toward a Theory of Hybridity". U of Wisconsin Legal Studies Research Paper, n. 1002, 2005).

${ }^{56}$ SHELTON, Dinah, op. cit., p.70.

${ }^{57} \mathrm{DOH}$, Jonathan; GUAY, Terrence. "Globalization and corporate social responsibility: How non-governmental organizations influence labor and environmental codes of conduct". En: Management and international review. Gabler Verlag, Wiesbaden, 2004. pp. 7-29.
} 
Las normas hard law presentan ventajas con relación a las normas soft law por poseer mayor uniformidad, con todo, la referida uniformidad puede ser una dificultad ante las incertidumbres y cambios rápidos de la actualidad ${ }^{58}$. Por otro lado, la flexibilidad es una característica importante de la soft law porque puede ajustarse con mayor facilidad a estos cambios, permitiendo el alcance de resultados más concretos y eficaces. En ese sentido, independiente del debate sobre la naturaleza jurídica de estas normas y de las obligaciones de que las organizaciones actúen con responsabilidad socioambiental, se verifica un creciente desarrollo de estándares, que funcionan como forma de soporte a diferentes demandas y procesos. Este soporte normativo privado ocurre esencialmente a través de la producción, adopción e implementación de instrumentos, directrices y herramientas esencialmente voluntarias.

Las normas técnicas y directrices dirigidas a las empresas han buscado fortalecer el diálogo entre las partes interesadas como: gobiernos, ONGs, consumidores, proveedores y trabajadores. Son normas construidas en procesos de diálogo, que auxilian la toma de decisiones, con el establecimiento de acuerdos sobre prácticas deseables, que pueden tener éxito si a partir de una estrecha y efectiva cooperación entre estas partes.

Los gobiernos suelen referenciar y/o incorporar normas técnicas en sus directrices y requisitos, como en el Reglamento (CE) no 1221/09 del Parlamento Europeo y del Consejo, de 25 de noviembre de 2009 "relativo la participación voluntaria de las organizaciones en un sistema comunitario y compartido de gestión y auditorías medioambientales (EMAS)" 59 . Este reglamento hace referencia explícita a la norma ISO 14001:2004: Sistemas de Gestión Ambiental - Requisitos con orientación para el uso ${ }^{60}$, indicando la aplicación directa de sus requisitos. ${ }^{61}$

\footnotetext{
${ }^{58}$ TRUBEK, David M.; COTTRELL, M. Patrick; NANCE, Mark, op. cit.

${ }^{59}$ DOPAZO FRAGUÍO, Pilar. "Gestión medioambiental y etiquetado ecológico: sistemas jurídicos europeos para promover la calidad ambiental (EMAS y EEE)". In: Derecho administrativo del medio ambiente: Temas y prácticas de actualidad jurídica. Servicio de Publicaciones de la Facultad de Derecho, 2018. pp. 81-110, p. 89.

${ }^{60}$ ISO. International Organiztion for Standardization. "ISO 14001: 2015: Environmental management systemsRequirements with guidance for use". Disponible en: $<$ https://www.iso.org/standard/60857.html $>$. Fecha de consulta: 20/01/2019.

${ }^{61}$ Vid. Anexo II del Reglamento (CE) No 1221/2009 del Parlamento Europeo y del Consejo de 25 de noviembre de 2009. Disponible en:< https://www.boe.es/doue/2009/342/L00001-00045.pdf >. Fecha de consulta: 12/02/2019.
} 
La Propuesta de Resolución (2018/2763(RSP) $)^{62}$ del Parlamento Europeo, sobre las actividades de las empresas transnacionales, considera en su documento otras iniciativas que también tratan de la RSC, entre ellas está la norma ISO 26000:2010 Orientación sobre Responsabilidad Social ${ }^{63}$.

La Directiva 2014/95/EU del Parlamento Europeo y del Consejo de 22 de octubre de 2014, también hace referencia a la utilización de normas técnicas para el cumplimiento de sus obligaciones. Dicha norma cría el deber de las organizaciones privadas, que se encuadran en los requisitos ${ }^{64}$ de la ley, emitir informaciones sobre cuestiones sociales y medioambientales. La referida Directiva cita normas voluntarias de iniciativa gubernamental o privada, incluyendo la norma ISO 26000:2010, con el objetivo de orientar a las organizaciones sobre el cumplimiento de las obligaciones referidas en la ley ${ }^{65}$.

\footnotetext{
${ }^{62}$ Vid. Resolución del Parlamento Europeo sobre la contribución de la Unión a un instrumento vinculante de las Naciones Unidas sobre las empresas transnacionales y otras empresas con características transnacionales con respecto a los derechos humanos (2018/2763(RSP)) (PE624.152/Rev. v 01-00). Disponible en: $<$ http://www.europarl.europa.eu/sides/getDoc.do?pubRef=-//EP//NONSGML+MOTION+B8-2018$0474+0+\mathrm{DOC}+\mathrm{PDF}+\mathrm{V} 0 / / \mathrm{PT}>$.

${ }^{63}$ La ISO 26000:2010: Orientación sobre Responsabilidad Social, diferentemente de la ISO 14001:2015: Sistemas de Gestión Ambiental - Requisitos con orientación para el uso, no es un estándar sobre sistema de gestión, tampoco es certificable, ya que su contenido no trae requisitos, sino, orientaciones sobre la responsabilidad social, promoviendo un entendimiento común acerca del tema. Posee un contexto de complementariedad de otros instrumentos normativos y no de sustitución. Es destinada a cualquier tipo y tamaño de organización y trae conceptos, definiciones, principios y prácticas acerca da responsabilidad social, resaltando la importancia de la definición de políticas de responsabilidad social por parte das organizaciones, así como la identificación, involucramiento y información a las partes interesadas. La norma ISO 26000: 2010: Orientación sobre Responsabilidad Social - "se destina a ayudar a las organizaciones a contribuir al desarrollo sostenible. Se trata de animarlos a ir más allá de la conformidad legal, reconociendo que el cumplimiento de la ley es un deber fundamental de cualquier organización y una parte esencial de su responsabilidad social." (ISO. International Organization for Standardization. ISO 2600:2010: Guidance on social responsibility. Disponible en:< https://www.iso.org/standard/42546.html >. Fecha de consulta: 20/01/2019).

${ }^{64}$ De acuerdo con la Directiva 2014/95/UE, las empresas que tengan más de 500 empleados están obligadas a publicar informes no financieros o relacionados con la responsabilidad social corporativa, que demuestren su desarrollo, la evolución y los resultados de sus actividades con referencia a las cuestiones sociales, medioambientales y derechos humanos, así como de la lucha contra la corrupción y el soborno. (DIRECTIVA 2014/95/UE del Parlamento Europeo y del Consejo, de 22 de octubre de 2014 por la que modifica la Directiva 2013/34/UE en lo que respecta a la divulgación de información no financiera e información sobre diversidad por parte de determinadas grandes empresas y determinados grupos. (DOUE (Diario Oficial de la Unión Europea) $330 / 1$ de $15 / 11 / 2014)$.

${ }^{65}$ La Directiva 2014/95/EU de 2014 también hace referencia a los marcos de la Unión Europea, como en el caso del Sistema de Gestión y Auditoría Medioambientales (EMAS - European Eco-Management and audit Scheme). (DOPAZO FRAGUÍO, Pilar. Gestión medioambiental..., op. cit., p. 87). Además hace referencia a los marcos internacionales (Pacto Mundial de las Naciones Unidas, los Principios Rectores sobre las empresas y los derechos humanos, las Directrices de la OCDE (Organización de Cooperación y Desarrollo Económicos para Empresas Multinacionales), la Declaración tripartita de principios sobre las empresas multinacionales y la política social de la (OIT) Organización Internacional del Trabajo, la Iniciativa Mundial de Presentación de Informes y otros marcos que sean internacionalmente reconocidos. (DIRECTIVA 2014/95/UE del Parlamento Europeo y del Consejo, de 22 de octubre de 2014 por la que modifica la Directiva 2013/34/UE en lo que respecta a la divulgación de
} 
A menudo, los estándares pueden ser vistos como complementos de otras normas o procesos $^{66}$. Diversas leyes se apoyan en esos instrumentos y valoran su capacidad de producir eficacia y efectividad, pues la eficacia de las normas está en su capacidad de producir efectos jurídicos y su efectividad, en obtener de forma sostenida los resultados que estén en conformidad con los objetivos establecidos ${ }^{67}$.

Además, las normas técnicas pueden surgir con anterioridad a la normativa legal. Ellas pueden incluso suplir vacíos $\mathrm{y} / \mathrm{o}$ deficiencias regulatorias ${ }^{68} \mathrm{y}$, muchas veces, inspirar la producción normativa legal. En este escenario, se verifica la adecuación de la soft law técnica como una alternativa o complemento a la ley, porque se adapta a los cambios y necesidades, supliendo lagunas jurídicas en situaciones más complejas ${ }^{69}$.

\section{LA AUTORREGULACIÓN DE LA RESPONSABILIDAD SOCIOAMBIENTAL COMO MECANISMO PARA LA GOBERNANZA Y LA CONFORMIDAD}

La regulación pública (heteroregulación) ${ }^{70}$ compone normas y políticas que estructuran el sistema jurídico y el funcionamiento adecuado del Estado. La regulación está, por consiguiente, relacionada con el papel del Estado y con la implementación y cumplimiento de sus comandos legales, que son vinculantes y tienen legitimidad en su elaboración, así como aplicabilidad a todos destinatarios. La decisión del Estado de actuar sobre la regulación de un sector o actividad específica se basa en la necesidad de proteger los bienes y/o derechos mediante la definición de reglas que se reflejan en las relaciones sociales para salvaguardar los intereses públicos.

\footnotetext{
información no financiera e información sobre diversidad por parte de determinadas grandes empresas y determinados grupos. (DOUE (Diario Oficial de la Unión Europea) 330/1 de 15/11/2014).

${ }^{66}$ KINGSBURY, Benedict; KRISCH, Nico; STEWART, Richard, op. cit.

${ }^{67}$ PEÑA CHACÓN, Mario. "El camino hacia la efectividad del derecho ambiental". Innovare: Revista de ciencia y tecnología, v. 5, n. 1, pp. 34-48, 2017.

${ }^{68}$ Los Estados Unidos lograron gran éxito con el programa de reducción de emisiones USEPA/TRI33/50 de 1991. Se trata de un programa voluntario que surgió como complemento a los reglamentos ambientales existentes. Estos programas pueden considerarse como alternativas de control que, incluso, son capaces de reducir los costos operativos. Las empresas se adhieren de forma voluntaria a estos instrumentos por razón de imagen y reputación, así como para ajustar sus sistemas de gestión de forma estratégica anticipando la conformidad con reglamentos futuros más rigurosos. (MCGUIRE, William. "The effect of ISO 14001 on environmental regulatory compliance in China”. Ecological Economics, v. 105, pp. 254-264, 2014).

${ }^{69}$ DE CAROLIS, Daniele, op. cit.

${ }^{70}$ Vid. EESC. European Economic and Social Committee. Opinion of the European Economic and Social Committee on Self-regulation and co-regulation in the Community legislative framework. Disponível em: $<$ https://eurlex.europa.eu/legal-content/EN/TXT/?uri=CELEX:52014IE4850>. Fecha de consulta: 28/11/2019.
} 
Por otro lado, el desarrollo de la actividad de regulación es lento, tiene altos costos de implementación y su aplicabilidad no excede a los límites de la jurisdicción nacional o regional ${ }^{71}$. A medida que las fronteras se vuelven porosas, se hace cada vez más difícil dominar unilateralmente los problemas más allá de estos límites. La forma tradicional de regulación, luego, resulta insuficiente para satisfacer las demandas globales, requiriendo complementación y apoyo para la implementación y realización de las agendas públicas internacionales.

El control de algunos temas y actividades, como en el caso de las empresas transnacionales, tiene demandado mayor cooperación internacional. El sistema de regulación en el ámbito de la RSC, por ejemplo, deriva de la producción normativa nacional y/o supranacional, que genera obligaciones sociales y ambientales para las empresas que, por supuesto, son obligadas a cumplir, ya que el compliance ${ }^{72}$ legal también forma parte de los intereses de diversos grupos, subrayando que la no atención a este deber puede llevar a sanciones y pérdidas económicas y reputacionales. Sin embargo, los límites del alcance de las normativas nacionales o supranacionales acaban siendo un problema para el efectivo control de las actividades de las empresas inseridas en otros territorios. Así, se nota la existencia de lagunas jurídicas sobre el enfrentamiento global de estas cuestiones.

Por otro lado, el proceso de autorregulación de la RSC se define ante los espacios libres da regulación estatal ${ }^{73}$, surgiendo, en grande medida, de deficiencias o dificultades de reglamentación, ya que aún no existe una forma concreta de garantizar un reglamento global efectivo de determinados temas, como en el caso de la $\mathrm{RSC}^{74}$. En este contexto, la autorregulación se estructura en normas privadas y compromisos de actuación asumidos espontáneamente, que se traducen en "normas voluntarias, códigos éticos y de conductas, entre otras posibles normas que definen y estructuran el autogobierno de una organización"75, con el objetivo de atender a las expectativas de los stakeholders.

\footnotetext{
${ }^{71}$ UGARTE, Sergio; SWINKELS, Vincent. Policy Instruments and Co-regulation for the Sustainability of Value Chains. New York: The American Society of Mechanical Engineers, 2015, p. 38.

${ }^{72}$ Compliance está relacionado con el cumplimiento de las obligaciones organizacionales, que son determinadas por las normas legales y por aquellas que la organización ha asumido de forma voluntaria e incorpora en su gestión (TEIJEIRA RODRÍGUEZ, Mariano, op. cit.).

${ }^{73}$ DARNACULLETA I GARDELLA, Mercé, p. 13.

${ }^{74}$ RUGGIE, John, op. cit., p. 18.

${ }^{75}$ DOPAZO FRAGUÍO, Pilar. La responsabilidad..., op. cit.
} 
La autorregulación también podrá surgir por demandas y presiones sociales que exigen comportamientos más responsables y éticos por parte de las empresas, y, asimismo, por competitividad, que está correlacionada con la necesidad de demonstrar condiciones suficientes de actuar en el mercado, con el fin de cumplir con sus obligaciones legales y con las expectativas de las partes interesadas. Por otra parte, la autorregulación de la RSC no se encuentra totalmente definida o unificada, es un proceso en marcha y que expresa esfuerzo para alinearse con otros sistemas más amplios de gobernanza. Por lo tanto, la autorregulación de las cuestiones socioambientales acaba fortalecida por el aumento de las prácticas de buena gobernanza y por el creciente número de organizaciones que empiezan a hacer parte de ese proceso ${ }^{76}$.

El incumplimiento de las obligaciones exigidas por la ley, o incluso de las que son asumidas de manera voluntaria, es capaz de producir daños económicos y reputacionales. Las empresas transnacionales además enfrentan una variedad de leyes y normas en los diferentes países en que hacen sus negocios, sin olvidar que la posibilidad del alcance de la extraterritorialidad de las leyes es un hecho cada vez más común. En este sentido, aumenta exponencialmente la producción de normas y estándares con el propósito de ayudar a las organizaciones a adecuarse a las demandas globales y a demostrar compromiso, buena gobernanza y compliance.

La formulación de estándares, códigos éticos, programas de cumplimiento y herramientas de gestión y control, que ayudan a las organizaciones en el cumplimiento de las exigencias legales y de las expectativas de los stakeholders, ha sido la forma encontrada para enfrentar las principales demandas de la actualidad. Al fin y al cabo, las normas técnicas son consideradas como "una de las muestras más genuinas de autorregulación"77. Su eficacia y competencia para orientar el cumplimiento de leyes e incluso para suplir posibles lagunas legales ${ }^{78}$ les conceden verdadera "relevancia pública"79.

\footnotetext{
${ }^{76}$ ANAD, Anita, op. cit.

${ }^{77}$ VIVES, Marc Tarrés. "Las normas técnicas en el Derecho Administrativo". Documentación administrativa, n. 265-266, 2003.

${ }^{78}$ TRUBEK, David; TRUBEK, Louise. "Hard and soft law in the construction of social Europe: the role of the open method of co-ordination”, European Law Journal, v. 11, n. 3, pp. 343-364, 2005.

79 VIVES, Marc Tarrés, op. cit.
} 
A menudo, un estándar de referencia es creado o desarrollado por una institución reconocida internacionalmente y conlleva en sus procesos de formulación transparencia, conocimiento técnico-científico y participación ampliada, imprimiendo su credibilidad, confiabilidad y aceptación. Son instrumentos que demuestran flexibilidad para adaptarse a un contexto complejo y volátil, donde las formas tradicionales de regulación pueden no actuar con la efectividad necesaria.

Son ejemplos de normas técnicas los estándares de la $\mathrm{ISO}^{80}$, sigla en inglés de International Organization for Standardization, un importante organismo internacional y no gubernamental de normalización, que ha contribuido vigorosamente con la autorregulación global de las actividades de las organizaciones privadas. Es una organización que actúa en diversas temáticas, sus estándares alcanzan gran aceptación en el mercado mundial. Las normas ISO presentan directrices orientativas y/o requisitos para la conformidad de inúmeros sistemas como de gestión de la calidad, medio ambiente, control de riesgos, corrupción y otros temas más técnicos ${ }^{81}$.

Los estándares son "especificaciones técnicas de adopción voluntaria, elaboradas por entidades reconocidas de carácter sectorial o multisectorial y de ámbito nacional, supranacional o internacional" ${ }^{2}$. Sirven como una especie de fórmula normativa específica para regular determinados sectores, muchos con características singulares, que no están al margen del proceso de gobernanza socioambiental global. Estos estándares surgen para ayudar a las organizaciones a atender a estas demandas, mejorar sus procesos y competitividad. Algunos de ellos anticipan las exigencias legales y acaban sirviendo de modelo o soporte para que las autoridades y gobiernos puedan llevar a cabo sus metas y compromisos.

\footnotetext{
${ }^{80}$ La ISO (International Organization for Standardization), con sede en Ginebra en Suiza, es considerada como uno de los más importantes organismos normativos internacionales. La organización ISO fue creada en 1946, luego de la Segunda Guerra Mundial y contó con la participación de 25 países. El objetivo fue crear un organismo internacional de estándares técnicos que sirvieran como parámetros globales de productos y servicios. La ISO cuenta hoy con representatividad de 162 países, a través de órganos de normalización internos. En Brasil, la ISO es representada por la ABNT - Asociación Brasileña de Normas Técnicas y en España por la UNE - Asociación Española de Normalización. La ISO tiene hoy un referencial de más de 22.000 normas internacionales publicadas. (ISO. International Organization for Standardization. About us. Disponible en: $<$ http://www.iso.org/iso/home.html >. Fecha de consulta: 10/11/2018).

${ }^{81}$ ISO. International Organization for Standardization. About us, op. cit.

${ }^{82}$ VIVES, Marc Tarrés, op. cit.
} 
Sobre la temática ambiental, se ha publicado la familia de normas técnicas ISO $14000^{83}$, considerada como la primera serie normativa internacional sobre la gestión ambiental $^{84}$. La norma ISO 14001:2015 - Sistemas de Gestión Ambiental - Requisitos con orientación para el uso - es un estándar certificable de la familia de normas ISO 14000. Su estructura define criterios y requisitos para implementación y mantenimiento del sistema de gestión medioambiental. Esta norma presenta una serie de principios aplicables a cualquier especie y tamaño de organización. Es una norma mundialmente conocida y aceptada, teniendo actualmente cerca de 300.000 certificaciones ${ }^{85}$.

Otra herramienta de la ISO, desarrollada con el objetivo de ayudar a las empresas a adecuarse a las cuestiones socioambientales, es la norma internacional ISO 26000:2010: Orientación sobre responsabilidad social. No se trata de una norma certificable, ya que no presenta requisitos para implantación de un sistema de gestión específico. La norma establece directrices de orientación con foco en el respeto a los derechos humanos, trabajo decente, protección ambiental, consumo y producción conscientes, cambio climático y desarrollo sostenible ${ }^{86}$. Las directrices de la norma ISO 26000:2010 fueron pensadas para la aplicación en toda especie y tamaño de organización, considerando su esfera de influencia y su responsabilidad con los impactos de sus actividades y sobre las cuales ejerce control directo, aunque no tenga autoridad legal para ello ${ }^{87}$.

El proceso de elaboración de la Norma ISO 26000:2010 duró cerca de 5 años y contó con un importante proceso de gobernanza, que ha promovido intensa y significativa participación de diversas partes interesadas, incluyendo gobiernos, empresas, ONGs, trabajadores y consumidores. Es una norma en sintonía con organizaciones internacionales como la Organización Internacional del Trabajo (OIT), el Pacto Global ${ }^{88}$, las directrices de la Organización para la Cooperación y Desarrollo

\footnotetext{
${ }^{83}$ ISO. International Organization for Standardization. ISO 14000 family - Environmental management. Disponible en: $<$ http://www.iso.org/iso/iso14000>. Fecha de consulta: 30/09/2018.

${ }^{84}$ ROBERTS, Hewitt; ROBINSON, Gary. ISO 14001 EMS: manual de sistemas de gestión medioambiental. Editorial Paraninfo, 1999, p.17.

${ }^{85}$ ISO. International Organization for Standardization. ISO 14001: 2015: Environmental management systemsRequirements, op. cit.

${ }^{86}$ INSTITUTO ETHOS. Empresas e Direitos Humanos na Perspectiva do Trabalho Decente. Artetexto Publicações. São Paulo: 2011, p. 07.

${ }^{87}$ RUGGIE, John, op. cit., p.24.

${ }^{88}$ El Pacto Global fue una iniciativa de las Naciones Unidas que lanzó en el año 2000 principios globales para las empresas para contribuir al desarrollo de la sociedad. John Ruggie, uno de los principales idealizadores de este
} 
Económico (OCDE) ${ }^{89}$ y con los Principios Orientadores de las Naciones Unidas para los Negocios y los Derechos Humanos ${ }^{90}$. Se trata de un estándar normativo que contó con la aprobación del $93 \%$ de los miembros de la ISO, incluida China.

En 2016, la ISO ha publicado también la norma ISO 37001:2016: Sistemas de gestión antisoborno - Requisitos con orientación para su uso. El objetivo de la norma es promover una cultura empresarial más ética y libre de soborno y corrupción. Es un estándar voluntario y certificable. La norma es aplicable a cualquier tipo y tamaño de organización, no siendo destinada solamente a las organizaciones privadas. Trata de la importancia del compromiso del liderazgo con el cumplimiento de sus directrices y requisitos y busca proporcionar a las organizaciones un sistema eficiente de gestión de riesgos y de conformidad ${ }^{91}$.

programa, afirma que el Pacto Global es "la mayor iniciativa de Responsabilidad Social Corporativa en el mundo", siendo planeada como un "foro de aprendizaje para la promoción de prácticas socialmente responsables en las áreas de derechos humanos, estándares para los lugares de trabajo, medio ambiente y anticorrupción". (RUGGIE, John, op. cit., p. 18).

${ }^{89}$ OCDE. Organización para la Cooperación y el Desarrollo Económicos. Líneas Directrices de la OCDE para Empresas Multinacionales, 2011. Disponible $<$ https://www.oecd.org/daf/inv/mne/MNEguidelinesESPANOL.pdf.pdf $>$ Fecha de consulta: 15/01/2019.

${ }^{90}$ Los Principios Orientadores de las Naciones Unidas para los Negocios y los Derechos Humanos, publicados en 2011, es la más reciente iniciativa establecida en el marco de las Naciones Unidas, con el objetivo de involucrar a las empresas en la adopción de medidas que garanticen la protección de los derechos humanos. En 2005, John Ruggie, profesor de la Universidad de Harvard, en Estados Unidos, recibió un mandato para ser el representante especial del secretario general de la ONU para empresas y derechos humanos. Su primer mandato fue hasta 2007, considerado como "fase de identificación y aclaración". El segundo fue de apenas un año para "desarrollar recomendaciones sobre mejores formas de desarrollar la pauta" (UN. United Nations. Guide, An Interpretive. The corporate responsibility to respect human rights, 2012, p. 52). A partir de los resultados positivos del trabajo, el Consejo decidió extender el mandato por otros tres años, con el objetivo de la concretización de los principios. Son 31 principios voluntarios que establecen el deber de los Estados en proteger y de las empresas en respetar los derechos humanos. Los Principios son aplicables a cualquier Estado o empresa y deben interpretarse "con el fin de mejorar los estándares y prácticas en relación con las empresas y los derechos humanos para alcanzar resultados tangibles para individuos y comunidades afectadas, y contribuir así a una globalización socialmente sostenible". Además, el proyecto propuso una guía para ayudar a las organizaciones a integrar los derechos humanos en la gestión del negocio. Esta guía trae orientaciones que pueden ser adoptadas por cualquier tipo de organización y ayudan a las empresas a adoptar acciones más proactivas sobre la protección de los derechos humanos en sus actividades. (CONECTAS. Empresas e Direitos humanos: parâmetros da ONU Proteger, respeitar e reparar. 2012, $\quad$ pp. 3-5. Disponible en: $<$ https://www.socioambiental.org/sites/blog.socioambiental.org/files/nsa/arquivos/conectas_principiosorientador esruggie_mar20121.pdf $>$. Fecha de consulta en: 17/01/2019). Los principios se consideran como un estándar mínimo a ser adoptado por las empresas de cualquier seguimiento y tamaño. El desarrollo de este trabajo se estableció en un proceso de gobernanza, que contó con la participación de empresas, gobiernos, ONGs y otros actores de la sociedad civil, interesados en la protección de los derechos humanos. El informe que contén los resultados de este trabajo se publicó en 2011 y presentó el deber de protección y respeto de los derechos humanos basado en "tres pilares": la obligación del Estado para proteger a las personas de las violaciones de derechos humanos; la responsabilidad de las empresas ante el deber de respetar los derechos humanos y la garantía del acceso de las víctimas de violaciones a los medios judiciales y extrajudiciales para obtener reparaciones (RUGGIE, John, op. cit., pp.14-24).

${ }^{91}$ La norma ISO 37001:2016: Sistemas de gestión antisoborno - Requisitos con orientación para su uso - es un estándar que concebido con el reto de ayudar a las organizaciones a luchar contra el soborno y promover una cultura empresarial ética y transparente. La norma se refiere al desarrollo y implementación de sistemas de gestión 
Se debe tener en cuenta, que estos estándares pueden contribuir de forma más precisa a determinados sectores o actividades, como también pueden dar impulso y/o mejores condiciones para el cumplimiento de la ley como en los casos vistos de la norma ISO 14001:2015 de gestión ambiental, que siempre ha sido utilizada como referencia y soporte para la aplicación de leyes. La ISO 37001:2016, por su vez, posee requisitos importantes para ayudar las organizaciones a alcanzar los objetivos de leyes, como es el caso del Código Penal español, que destaca la responsabilidad de la persona jurídica en promover y utilizar modelos de control adecuados y efectivos para evitar la corrupción y soborno de forma que no le incurra la responsabilidad penal, sirviendo su efectiva implementación, incluso, como un factor atenuante. ${ }^{92}$

Las normas técnicas se diferencian de las normas legales por su carácter voluntario y, a principio, no vinculante. Sin embargo, la compatibilidad y posibilidad de integración entre estas distintas normas es plenamente reconocida ${ }^{93}$. La dinámica y flexibilidad de estas herramientas hacen la condición necesaria para su proyección, facilitando la combinación con otras normas, incluso legales, permitiendo, por otra parte, la transposición del debate sobre hard law y soft law ${ }^{94}$, así como el logro de los objetivos y finalidades de su concepción.

La construcción de una autorregulación, apoyada en la gobernanza global, aunque con limitaciones, permite avances en los asuntos que han sido gestionados, y, sobre todo, contribuye al incremento y fortalecimiento de la "globalización jurídica"95. La

contra el soborno, que especifica una medidas y requisitos para ayudar en la prevención, detección y tratamiento de asuntos relacionados al soborno, a través de la adopción de política contra el soborno, capacitación, evaluaciones de riesgo y implementación de controles operacionales y financieros, con procedimientos de documentación, de informes e investigación. La norma ISO 37001:2016 es certificable y puede ser utilizada por cualquier organización, de cualquier tamaño y sector. (ISO. International Organization for Standardization. ISO 37001 - Anti-bribery management systems: Requirements with guidance for use. Disponible en: $<$ https://www.iso.org/iso-37001-anti-bribery-management.html $>$ Fecha de Consulta 19/11/2018).

${ }^{92}$ Vid. artículo 31 bis del Código Penal (BOE-A-1995-25444), modificado por la Ley Orgánica 5/2010, de 22 de junio de 2010 (BOE-A-2010-9953). Disponible en: $<$ https://www.boe.es/buscar/doc.php?id=BOE-A-20109953>. Fecha de consulta: 10/02/2019.

${ }^{93}$ DOPAZO FRAGUÍO, Pilar. Gestión medioambiental..., op. cit., p. 87.

${ }^{94}$ TRUBEK, David; TRUBEK, Louise. "Hard and soft law in the construction of social Europe, op. cit.

${ }^{95} \mathrm{La}$ globalización jurídica puede definirse como el aumento del número de reglas internacionales públicas o privadas que buscan reglamentar asuntos internacionales de interés común. (MATIAS, Eduardo Felipe, op. cit., p. 123). Con la globalización se nota el surgimiento de temas que necesitan de gerenciamiento colectivo y que cuentan con la participación y cooperación de múltiples agentes. Este proceso acaba por generar otras formas de regulación que extrapolan la manera tradicional de reglamentar hecha aisladamente por los Estados. Se puede decir que, así como ocurre la transnacionalización de los mercados, informaciones y tecnologías, también ocurre la transnacionalización de la reglamentación. Este escenario jurídico global hace distinto porque es capaz de impulsar y conjugar diferentes tipos normativos públicos y privados, comportando diferentes especies de organizaciones formales e informales (GUICHOT, Emilio. "Globalización jurídica y Derecho público. Recientes aportaciones en la doctrina europea". Revista de administración pública, n. 187, pp. 305-326, 2012). La globalización jurídica o 
globalización jurídica es un fenómeno que "obliga a una reestructuración de las ciencias jurídicas en línea con los nuevos entornos globales y transnacionales"96. Este proceso acaba por generar un aumento en la actividad normativa privada (soft law) creando un sistema jurídico híbrido, debido a la conjugación de tipos normativos de origen público-privado97. Este sistema jurídico híbrido es comprendido pela construcción de normas comunes que afectan derechos nacionales susceptibles a adoptar comandos de normas técnicas regionales o, incluso, internacionales ${ }^{98}$.

Hay que señalar que la norma alcanza o puede alcanzar "significación jurídica cuando desde una norma del ordenamiento jurídico se hace remisión a ella ${ }^{99}$. Además, la "actividad de autorregulación"100, aunque impulsada por la falta de regulación estatal específica, desempeña un papel importante por contribuir a que las organizaciones se preparen para atender demandas internas y externas, sirviendo, igualmente, como mecanismo de atendimiento a exigencias públicas, provocando la "autorregulación regulada", ${ }^{101}$ es decir, "una autorregulación inducida a la que desde el poder público se le imponen unas determinadas exigencias de procedimiento y contenido"102.

El control de las actividades empresariales debe estructurarse en un sistema de producción normativa que busca orientar, coordinar y organizar las prácticas de las organizaciones. Sin embargo, este sistema, "en lugar de expresión exclusiva de la soberanía del Estado"103, tiene se convertido cada vez más en el producto de la

\footnotetext{
globalización del derecho se delinea y concretiza en el alargamiento de la producción normativa $\mathrm{y}$, consecuentemente, por la posibilidad de coexistencia de la regulación y autorregulación. Trata-se de un proceso normativo formado por una multiplicidad de productores de normas, con superación del monopolio estatal (Ibídem).

${ }^{96}$ CLERC, Carlos. "El Derecho Internacional Privado y los procesos globalizadores". Prolegómenos, v. 16, n. 32, pp. 15-30, 2013.

${ }^{97}$ KINGSBURY, Benedict; KRISCH, Nico; STEWART, Richard, op. cit.

${ }^{98}$ VÁZQUEZ, María del Ángel Iglesias. "Globalización, globalización jurídica, global law y derecho internacional privado". Cuadernos de derecho transnacional, v. 9, n. 1, pp. 215-235, 2017.

${ }_{99}$ VIVES, Marc Tarrés. Las normas técnicas..., op. cit.

${ }^{100}$ DOPAZO FRAGUÍO, Pilar. "Responsabilidad Empresarial por Riesgos Ambientales en España", op. cit.

${ }^{101}$ Autorregulación Regulada es un término que define la influencia del poder público en la actividad de autorregulación, o sea, es cuando el Estado toma en consideración el control y la producción normativa ejecutada pelo sector privado. En la autorregulación regulada ocurre el reconocimiento de la norma privada y de sus contribuciones para los asuntos de interés públicos y sociales, habiendo la adopción o remisión de las normas autorreguladas en las normas legales, provocando el fenómeno de la desregulación (PARDO, José Esteve. Autorregulación. Génesis y efectos, Thomson Reuters-Aranzadi, Navarra, 2002, pp. 26-29). Por lo tanto, la autorregulación regulada "se concreta en una actividad legislativa y administrativa que dota a la autorregulación privada de un marco y unas garantías que permiten tomarla como referencia con carácter general" (PARDO, José Esteve. "La administración garante. Una aproximación". Revista de administración pública, n. 197, pp. 11-39, 2015).

${ }^{102}$ Ibídem.

${ }^{103}$ DE CAROLIS, Daniele, op. cit.
} 
interacción entre diferentes actores, generando un proceso de corregulación dinámico y pragmático, que conlleva los sistemas de regulación y autorregulación.

En este contexto se encuentra una línea tenue sobre la regulación y autorregulación de la RSC, puesto que este espacio de fusión entre las dos categorías permite identificar la necesidad de atención a intereses convergentes sobre la conformidad legal, además de otros aspectos que están en torno de los compromisos asumidos voluntariamente. De esta forma, la RSC se torna un régimen híbrido, que congrega leyes y estándares, estos últimos, por su parte, siempre correlacionados e implicadas con las leyes, normas y programas internacionales, así como con el interés de los stakeholders. Consecuentemente, se verifica un proceso de constante interrelación y alineamiento normativo, donde no están tan claros y precisos los límites y avances de esa especie normativa soft law. Sin embargo, su fuerza y eficacia en el ámbito de las organizaciones privadas es incontestable, tanto por su frecuente desarrollo como por su diseminación y aceptación de los actores involucrados.

Las normas técnicas ISO se construyen desde procesos conjuntos de participación pública y privada, que cuentan con expertos sobre la temática. Este proceso de construcción normativa demuestra gran esfuerzo de la comunidad global por la ordenación de prácticas capaces de conducir al logro de soluciones eficaces para problemas tan complejos. Son herramientas que buscan auxiliar a las organizaciones en la construcción e implementación de acciones, que permitan mejorar la gestión sobre riesgos ambientales y sociales, contribuyendo efectivamente a la protección de los derechos humanos, del medio ambiente y al desarrollo sostenible.

En este contexto, la gobernanza global, vista como una forma de gobierno conjunto, pragmático y orientado a la participación, cooperación y promoción de consensos, se torna un proceso que permite la coexistencia de sistemas distintos de regulación que, al final, congregan intereses distintos, pero, con el mismo objetivo de enfrentar problemas globales ${ }^{104}$. Por lo tanto, es, sin duda, indispensable para los procesos de gobernanza que las empresas estén presentes, participen activamente $y$, principalmente, incorporen los objetivos sociales y ambientales a sus políticas y estrategias. Además, la construcción del modelo autorregulatorio eficiente "requiere una nueva dinámica en la relación entre Estado, mercado y sociedad civil"105, capaz

\footnotetext{
${ }^{104}$ FRIEDRICH, Jürgen, op. cit., p.19.

${ }^{105}$ INSTITUTO ETHOS, op. cit., p. 41.
} 
de permitir una especie de "corregulación" entre gobiernos y organizaciones privadas, que contribuya para la eficacia de la implementación de la responsabilidad socioambiental corporativa, reforzando su significado y funcionalidad dentro del contexto del desarrollo sostenible $\cdot 106$

\section{CONCLUSIONES}

La globalización y sus efectos proporcionaron cambios en la forma de acción de las organizaciones que demandan controles más seguros sobre los riesgos. Se encuentra en este escenario, además de una oportunidad de avance y destaque, innumerables otras responsabilidades que son intrínsecas a la forma de desempeño transnacional. En este sentido, por diversos factores internos y externos, patente es la necesidad de tener en cuenta los impactos de las actividades y, sobretodo, las expectativas de los stakeholders. No demostrar la atención a esa demanda puede tener consecuencias que superen las preocupaciones por las sanciones, que puedan derivarse del incumplimiento de instrumentos legales.

La transnacionalización de las organizaciones trae la dificultad de control de las actividades empresariales y sus impactos, situación que agrava sobremanera los problemas socioambientales. Igualmente, la complejidad del tema de RSC y su enfrentamiento por la comunidad internacional generan lagunas legales, debido a la dificultad de establecer una reglamentación jurídica común, que permita el control de las actividades empresariales. Este contexto termina por ampliar cada vez más las responsabilidades de las organizaciones, provocando el surgimiento de iniciativas y herramientas que acaban ejerciendo influencia para que un creciente número de organizaciones asuman compromisos para demostrar la conformidad de sus actividades.

En este sentido, el presente artículo ha demostrado el contexto de herramientas soft law utilizadas para el enfrentamiento de los problemas socioambientales globales y su influencia en la estructuración legal y voluntaria de la RSC. Para ello, se realizó un

\footnotetext{
${ }^{106}$ DOPAZO FRAGUÍO, Pilar; REI, Fernando. "Transparencia informativa de las organizaciones: el rol de los informes corporativos en materia de" responsabilidad social empresarial"(RSE)". Revista Aranzadi de Derecho Ambiental, $\mathrm{n}^{\circ} .24$, pp. 303-338, 2013.
} 
levantamiento de los principales temas relacionados con el desarrollo sostenible, apuntando para la necesidad del establecimiento de una gobernanza conjunta de estos asuntos, así como se enfatizó la importancia de la autorregulación en este proceso. La autorregulación quedó demostrada como una realidad creciente que surge de forma paralela a la regulación estatal, pero no disociada. Su importancia se manifiesta de forma fundamental para sumar a las agendas socioambientales, así como para incluir a las organizaciones privadas de forma práctica y efectiva en la persecución de sus objetivos y, sobre todo, en el proceso de cooperación multinivel, que estructura la gobernanza global.

El análisis de la autorregulación de la responsabilidad socioambiental identificó que ese proceso está alineado e interrelacionado con los objetivos de la gobernanza global. Además, la autorregulación privada demuestra alineamiento en el establecimiento de directrices que siguen las más importantes normas internacionales, considerando siempre las diferentes expectativas y la participación de actores estatales y no estatales en los diálogos y consensos que son establecidos en su formulación.

Por lo tanto, las iniciativas aquí demostradas indican gran potencial de estandarización y difusión de prácticas empresariales sostenibles relacionadas con los objetivos globales socioambientales. Estas herramientas, traducidas en instrumentos técnicos voluntarios, contribuyen, en su medida, a suplir a la laguna jurídica identificada. Su formación cuenta con procesos amplios de gobernanza que, a su vez, proporcionan un cierto grado de integración normativa soft law y hard law para facilitar la gestión y compliance por parte de las organizaciones. Sin embargo, estas herramientas no se construyen de forma disociada de la normativa jurídica estatal, al revés, se interrelacionan con otras normas voluntarias y/o legales con el reto de dar estructura y contribuir a la conformidad de la gestión organizacional.

Estos estándares crean un sistema de autorregulación de las prácticas organizacionales que auxilia en la gestión corporativa, dando mayor transparencia, uniformidad y eficiencia en sus prácticas, y, consecuentemente, en el logro de los objetivos propuestos. Son herramientas voluntarias que actúan como un anillo entre la normativa obligatoria y otras normas internacionales de comportamiento que, por diversas razones, aún no logran abarcar de forma completa y eficaz el control de la RSC. 
En este caso, las normas técnicas tienen como regla principal la conformidad legal y el objetivo de contribuir a la buena gobernanza, ayudando a las organizaciones en la gestión de los riesgos, control interno y persecución de los objetivos, considerando siempre su entorno y los stakeholders. Son herramientas que buscan dar soporte a las organizaciones en la implementación de la gestión corporativa ética, eficiente y orientada a la adopción de prácticas sostenibles, alineadas con estándares y normas internacionales de comportamiento, buscando siempre evitar consecuencias e impactos negativos no sólo para el medio ambiente y la sociedad, pero, sobre todo, para la sostenibilidad de los negocios.

El análisis realizado de los conceptos que permean ese fenómeno normativo, cada vez más frecuente, demuestra su importancia y posibilidades de producir efectos eficaces en ese escenario. Esto es porque las normas privadas no solo se limitan a atender los objetivos legales, sino también las expectativas de las partes interesadas que, de una forma o de otra, están de acuerdo con los intereses globales de protección medioambiental y de derechos humanos. Ellas surgen con gran potencialidad de fomentar y desarrollar el alcance y efectividad de las normas y programas legales que, por su vez, a través de una especie de autorregulación regulada, buscan la inscripción de compromisos obligatorios a las organizaciones en un contexto de responsabilidades compartidas y fortalecidas.

Por lo tanto, la RSC ha sido regulada de forma directa y indirecta, respectivamente a través de normas legales y herramientas técnicas que buscan, muchas veces de forma conjunta, ayudar a las organizaciones en el cumplimiento de las expectativas de los stakeholders. De esta forma, es posible percibir la concreta funcionalidad de estas herramientas técnicas soft law y su influencia y alcance en una actividad normativa corregulada, que sea mucho más efectiva para el sector. Además, la relación entre la regulación y autorregulación de las prácticas de RSC y su contribución para la efectividad de las propuestas globales sobre el desarrollo sostenible, son asuntos que pueden ser explorados en estudios futuros, con el objetivo de demostrar de forma práctica y ejemplificativa la identificada correlación y beneficios entre las especies normativas hard y soft, en el enfrentamiento de los problemas socioambientales. 


\section{REFERENCIAS BIBLIOGRÁFICAS}

ABNT. Associação Brasileira De Normas Técnicas. NBR ISO 26000: Diretrizes sobre responsabilidade social. Rio de Janeiro: ABNT, 2010.

ANAD, Anita. "Voluntary vs Mandatory Corporate Governance: Towards an Optimal Regulatory Framework", American Law \& Economics Association Annual Meetings, n.44, 2005.2 Disponible en: <http://law.bepress.com/cgi/viewcontent.cgi?article=1537\&context=alea>. Fecha de consulta: 25/10/ 2018.

BARRANCO, Mata et al. Derecho penal económico y de la empresa. Madrid: Editorial Dykinson, 2018.

BEYERLIN, Ulrich; MARAUHN, Thilo. International Environmental Law. Oxford: Hart Publishing, 2011.

BIERMANN, Frank. "Global Environmental Governance. Conceptualization and Examples". Global Governance Working Paper No 12. Amsterdam, Berlin, Oldenburg, Potsdam: The Global Governance Project, 2004. Disponible en:< www.glogov.org>. Fecha de consulta: 24/09/2018.

BOISTER, Neil. An introduction to transnational criminal law. Oxford University Press, 2012.

CARROLL, Archie. "A three-dimensional conceptual model of corporate performance". Academy of management review, v. 4, n. 4, pp. 497-505, 1979.

CLERC, Carlos. "El Derecho Internacional Privado y los procesos globalizadores”. Prolegómenos, v. 16, n. 32, pp. 15-30, 2013.

CMMAD. Comissão Mundial sobre Meio Ambiente e Desenvolvimento. Nosso futuro comum. Rio de Janeiro: Editora da Fundação Getúlio Vargas, 1991.

CONECTAS. Empresas e Direitos humanos: parâmetros da ONU Proteger, respeitar e reparar. 2012. Disponible en: < https://www.socioambiental.org/sites/blog.socioambiental.org/files/nsa/arquivos/co nectas_principiosorientadoresruggie_mar20121.pdf $>$. Fecha de consulta en: $17 / 01 / 2019$. 
DARNACULLETA I GARDELLA, Mercé. Derecho Administrativo y Autorregulación: La Autorregulación regulada. (Tesis Doctoral). Girona: Universidad de Girona. Departamento de Derecho Público. 2002.

DE CAROLIS, Daniele. "Some Features of the Harmonisation of International Trade Law in the Third Millennium". Unif. L. Rev., v. 15, p. 37, 2010.

DOH, Jonathan; GUAY, Terrence. "Globalization and corporate social responsibility: How non-governmental organizations influence labor and environmental codes of conduct". En: Management and international review. Gabler Verlag, Wiesbaden, pp. 7-29, 2004.

DOPAZO FRAGUÍO, Pilar. "Gestión medioambiental y etiquetado ecológico: sistemas jurídicos europeos para promover la calidad ambiental (EMAS y EEE)”. In: Derecho administrativo del medio ambiente: Temas y prácticas de actualidad jurídica. Servicio de Publicaciones de la Facultad de Derecho, pp. 81-110, 2018.

- "La responsabilidad social corporativa (RSC) como activo facilitador de la innovacioón jurídica". REJIE: Revista Jurídica de Investigación e Innovación Educativa, n. 13, pp. 31-48, 2016.

- "Informes de responsabilidad social corporativa (RSC): fuentes de información y documentación". Revista general de información y documentación, v. 22, pp. 279-305, 2012.

. "Responsabilidad Empresarial por Riesgos Ambientales en España: Implicaciones Jurídicas y Estratégicas". Revista de Estudos Jurídicos UNESP, v. 14, n. 20, 2011.

DOPAZO FRAGUÍO, Pilar; REI, Fernando. "Transparencia informativa de las organizaciones: el rol de los informes corporativos en materia de "responsabilidad social empresarial" (RSE)". Revista Aranzadi de Derecho Ambiental, nº. 24, pp. 303-338, 2013.

ELKINGTON, John. Canibais com garfo e faca: seria um sinal de progresso se um canibal utilizasse garfo e faca para comer? São Paulo: Makron Books, 2001.

FREEMAN, R. Edward. "The stakeholder approach revisited". Zeitschrift für Wirtschafts-und Unternehmensethik, v. 5, n. 3, pp. 228-254, 2004. 
FRIEDRICH, Jürgen. International Environmental "soft law": The Functions and Limits of Nonbinding Instruments in International Environmental Governance and Law. Springer Science \& Business Media, 2013.

GEIGEL, Nelson. Derecho ambiental internacional. Universidad Simón Bolívar. Ediciones Equinoccio. Venezuela, 1997.

GILLAN, Stuart et al. "Firms' environmental, social and governance (ESG) choices, performance and managerial motivation". Unpublished working paper, 2010.

GONÇALVES, Alcindo. "Governança Global", en: GONÇALVES, Alcindo e COSTA, José Augusto Fontoura, Governança Global e Regimes Internacionais. São Paulo: Almedina, 2011.

GSIA. Global Sustainable Investment Alliance. Global Sustainable Investment Review, 2016. Disponible en: <http://www.gsi-alliance.org/wpcontent/uploads/2017/03/GSIR_Review2016.F.pdf >. Fecha de consulta 15/01/2019.

GUICHOT, Emilio. "Globalización jurídica y Derecho público. Recientes aportaciones en la doctrina europea". Revista de administración pública, n. 187, pp. 305-326, 2012.

INSTITUTO ETHOS. Empresas e Direitos Humanos na Perspectiva do Trabalho Decente. Artetexto Publicações. São Paulo: 2011. Disponible en: < https://www.ethos.org.br/wp-content/uploads/2012/12/04_Empresas-e-DireitosHumanos-na-Perspectiva-do-Trabalho-Decente-\%E2\%80\%93-MarcoReferencial.pdf $>$. Fecha de consulta 18/11/ 2018

ISO. International Organization for Standardization. ISO 2600:2010: Guidance on social responsibility. Disponible en:< https://www.iso.org/standard/42546.htmll>. Fecha de consulta: 20/01/2019.

. ISO 26000:2010(es)- Guía de responsabilidad social. Disponible en: $<$ https://www.iso.org/obp/ui\#iso:std:iso:26000:ed-1:v1:es>. Fecha de consulta: 02/12/2019.

ISO 14000 family - Environmental management. Disponible en:<http://www.iso.org/iso/iso14000>. Fecha de consulta: 30/09/2018. 
. ISO 14001: 2015: Environmental management systems- Requirements with guidance for use. Disponible en:<https://www.iso.org/standard/60857.html>. Fecha de consulta: 20/01/2019.

. ISO 37001 - Anti-bribery management systems. Anti-bribery management systems - Requirements with guidance for use. Disponible en:<https://www.iso.org/iso-37001-anti-bribery-management.html> Fecha de Consulta 19/11/2018.

KINGSBURY, Benedict; KRISCH, Nico; STEWART, Richard. "The emergence of global administrative law". Law and contemporary problems, v. 68, n. 3/4, pp. 1561, 2005.

LEIBOLD, Annalisa. "Extraterritorial Application of the FCPA Under International Law". Willamette L. Rev., v. 51, pp. 225, 2014.

LIMA, Luciana; REI, Fernando. "O Papel da Soft Law privada no Enfrentamento da Problemática Socioambiental Global". Revista Eletrônica Direito e Política, v. 13, n. 2, pp. 855-879, 2018.

MATIAS, Eduardo Felipe. A humanidade e suas fronteiras: do Estado soberano à sociedade global. $4^{\text {a }}$ ed. São Paulo: Paz e Terra, 2014.

MCGUIRE, William. "The effect of ISO 14001 on environmental regulatory compliance in China". Ecological Economics, v. 105, pp. 254-264, 2014.

NAVARRO GARCÍA, Fernando. Responsabilidad social corporativa: teoría y práctica. ESIC editorial, 2012.

OCDE. Organización para la Cooperación y el Desarrollo Económicos. Líneas Directrices de la OCDE para Empresas Multinacionales, 2011. Disponible en: $<$ https://www.oecd.org/daf/inv/mne/MNEguidelinesESPANOL.pdf.pdf> Fecha de consulta: 15/01/2019.

PARDO, José Esteve. Autorregulación. Génesis y efectos, Thomson ReutersAranzadi, Navarra, 2002.

. "La administración garante. Una aproximación". Revista de administración pública, n. 197, pp. 11-39, 2015. 
PEÑA CHACÓN, Mario. "El camino hacia la efectividad del derecho ambiental". Innovare: Revista de ciencia y tecnología, v. 5, n. 1, pp. 34-48, 2017.

ROBERTS, Hewitt; ROBINSON, Gary. ISO 14001 EMS: manual de sistemas de gestión medioambiental. Editorial Paraninfo, 1999.

RUGGIE, John. Quando os Negócios não são Apenas Negócios: as Corporações Multinacionais e os Direitos Humanos. São Paulo: Editora Planeta Sustentável, 2014.

SAND, Peter $\mathrm{H}$. The history and origin of international environmental law. Edward Elgar Pub. Limited, 2015.

SHELTON, Dinah. "Soft law". In: Routledge handbook of international law. Routledge, pp. 99-111, 2009.

SILVEIRA ANDRADE, Jose Célio. "Participação do setor privado na governança ambiental global: Evolução, contribuições e obstáculos". Contexto Internacional, v. $31, n^{\circ} .2,2009$.

TEIJEIRA RODRÍGUEZ, Mariano. "Responsabilidad social corporativa y compliance legal (autorregulación y control interno)". In: Derecho administrativo del medio ambiente: Temas y prácticas de actualidad jurídica. Servicio de Publicaciones de la Facultad de Derecho, pp. 219-240, 2018.

TRUBEK, David; COTTRELL, Patrick; NANCE, Mark. "Soft Law, Hard Law, 'and European Integration: Toward a Theory of Hybridity". U of Wisconsin Legal Studies Research Paper, n. 1002, 2005.

TRUBEK, David; TRUBEK, Louise. "Hard and soft law in the construction of social Europe: the role of the open method of co-ordination", European Law Journal, v. 11, n. 3, pp. 343-364, 2005.

VÁZQUEZ, María del Ángel Iglesias. "Globalización, globalización jurídica, global law y derecho internacional privado". Cuadernos de derecho transnacional, v. 9, n. 1, pp. 215-235, 2017.

VILLAS BÔAS FILHO, Orlando, "As transformações da regulação jurídica na sociedade contemporânea: a governança como paradigma". Revista Direito GV, [S.I.], v. 12, n. 1, pp. 251-259, fev. 2016. ISSN 2317-6172. Disponible en:< 
http://bibliotecadigital.fgv.br/ojs/index.php/revdireitogv/article/view/59462/57853>. Fecha de consulta: 27/09/2018.

VIVES, Marc Tarrés. "Las normas técnicas en el Derecho Administrativo". Documentación administrativa, n. 265-266, 2003.

UNESCAP. United Nations Economic and Social Commission for Asia and the Pacific. What is Good Governance? Disponible en:<https://www.unescap.org/sites/default/files/good-governance.pdf>. Fecha de consulta: 20/11/2018.

UGARTE, Sergio; SWINKELS, Vincent. Policy Instruments and Co-regulation for the Sustainability of Value Chains. New York: The American Society of Mechanical Engineers, 2015.

WEISS, Thomas. "Governance, good governance and global governance: conceptual and actual challenges". Third world quarterly, v. 21, n. 5, pp. 795-814, 2000. 